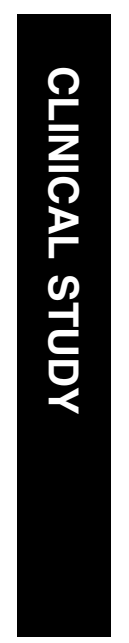

${ }^{1}$ Department of Ophthalmology and Visual Sciences, Prince of Wales Hospital, Shatin, Hong Kong, PRC

${ }^{2}$ Department of Ophthalmology and Visual Sciences, Hong Kong Eye Hospital, Kowloon, Hong Kong, PRC

${ }^{3}$ Orbital and Ophthalmic Plastic Surgery Division, Jules Stein Eye Institute, University of California at Los Angeles, Los Angeles, CA, USA

Correspondence: DSC Lam, Department of Ophthalmology and Visual Sciences, The Chinese University of Hong Kong, 3/F Hong Kong Eye Hospital, 147K Argyle Street, Kowloon, Hong Kong, PRC. Tel: + 868522762 3157; Fax: + 8685227623068 . E-mail: dennislam_pub@ cuhk.edu.hk

Received: 21 November 2008

Accepted in revised form:

5 February 2009

Published online: 20 March 2009

Presented as free paper presentation during the Annual Scientific meeting of the American Academy of Ophthalmology at New Orleans, 2007

\section{Unilateral ptosis correction with mersilene mesh frontalis sling in infants: thirteen-year follow-up report}

\begin{abstract}
Purpose To assess surgical, visual, refractive, and aesthetic outcomes $\mathbf{1 3}$ years after mersilene mesh frontalis sling (MMFS) operation for severe unilateral congenital ptosis performed in 10 infants before 1 year of age.

Methods Longitudinal follow-up of an interventional case series by structured ocular examinations, external photographs, and questionnaire-based interviews.
\end{abstract}

Results Mean age at surgery was $6.9 \pm 2.7$ months. After a mean follow-up of $\mathbf{1 3 . 0} \pm \mathbf{0 . 6}$ years, one patient $(\mathbf{1 0 \%})$ had recurrent ptosis with the upper lid $2 \mathrm{~mm}$ below the superior limbus at 3 months postoperatively.

Best-corrected visual acuities were within two Snellen lines between the two eyes in all patients. Astigmatic errors were $1.20 \pm 1.00 \mathrm{D}$ and 1.10 $\pm 1.70 \mathrm{D}$ between operated and unoperated eyes. Four patients had $2 \mathrm{~mm}$ lid lag on down-gaze and one of them had $2 \mathrm{~mm}$ lagophthalmos. Mean satisfaction scores (scale of 1 to 100) for lid position, cosmesis, function, and to the procedure were $83.3 \pm 11.8$,

$77.0 \pm 22.9,89.4 \pm 5.5$, and $86.8 \pm 6.3$, respectively. No case of overcorrection, sling extrusion, stitch granuloma, or exposure keratopathy was noted.

Conclusions In view of the low recurrence rate $(\mathbf{1 0 \%})$ and absence of serious complication or need for revision after 13 years, the use of MMFS seems effective and feasible in infants less than 1 year old. Achieving compatible long-term stability, satisfactory aesthetic, and visual outcomes, MMFS may offer an alternative to delaying operations for autogenous fascia lata harvesting in infants requiring early ptosis correction.
KKL Chong ${ }^{1,3}$, DSP Fan², CHY Lai ${ }^{1}$, SK Rao², PTH Lam ${ }^{1}$ and DSC Lam,
Eye (2010) 24, 44-49; doi:10.1038/eye.2009.48; published online 20 March 2009

Keywords: Blepharoptosis; congenital disorders; mersilene; surgical meshes

\section{Introduction}

Frontalis suspension (FS) is preferred by many surgeons for the treatment of congenital blepharoptosis owing to the poor levator function $(<4-6 \mathrm{~mm}) \cdot{ }^{1-3}$ At present, the gold standard of suspensory material is autologous fascia lata (AFL) owing to its superior stability and cosmetic results. ${ }^{1-6}$ Not all children are suitable candidates, as the fascia lata is generally not well developed enough before 3 years of age. ${ }^{1-3}$

Mersilene Mesh (MM: Ethicon, Somerville, NJ, USA) is a synthetic non-absorbable macro-mesh (polyester) widely used in general vascular and orthopaedic surgery.

It is inexpensive, easy to handle, and can be sterilized. ${ }^{7}$ Tensile strength reduces $<4 \%$ after the first year of implantation and the sling is unlikely to lengthen with time causing ptosis recurrence. Moreover, it serves as a permanent scaffold for fibrovascular ingrowth promoting tissue incorporation. ${ }^{4,8-15}$

Banked fascia lata or sclera and synthetic materials like monofilament nylon, polyfilament cable-type nylon suture (Supramid Extra), braided polyester, expanded polytetrafluroethylene (Gore-tex), polypropylene, and silicone $\operatorname{rod}^{4,5}$ have been used as alternative sling materials, with a higher rate of ptosis recurrence and soft tissue complications in the long run compared with AFL. 
We reported our mid-term results (mean follow-up: 40.3 months) of severe unilateral congenital ptosis correction using mersilene mesh frontalis sling (MMFS) in infants $<1$ year of age (Figure 1). ${ }^{8}$ In the current study, we would like to assess long-term surgical outcome, patients' satisfaction, and their refractive and visual development after infantile unilateral ptosis correction. ${ }^{16,17}$

\section{Materials and methods}

The original study was a non-randomized, interventional consecutive case series conducted at the Prince of Wales

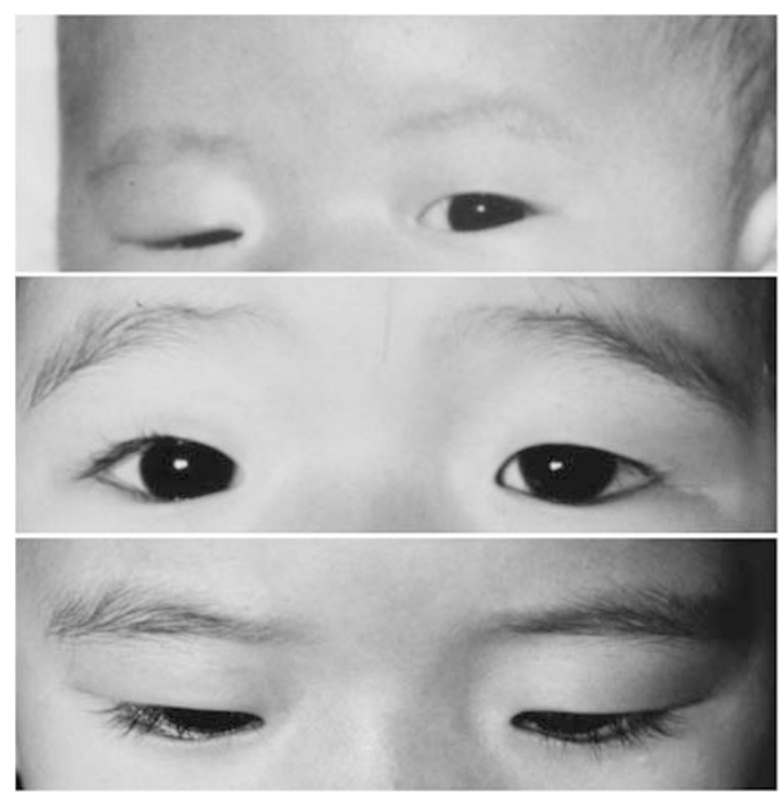

Figure 1 An infant with right-sided severe ptosis preoperatively (above) and 6 months postoperatively (central, below). Note successful correction of ptosis with preservation of lid crease and contour features (central); no appreciable lid lag on down-gaze (below).
Hospital, Hong Kong, between 1992 and 1994. ${ }^{8}$ MMFS operations were performed as the primary treatment by the senior author (DSCL) in 10 consecutive infants suffering from severe unilateral simple congenital ptosis obscuring visual axis or causing a chin-up position. The amount of ptosis was estimated by comparing the upper lid position between the two eyes in primary gaze. (Table 1) All the subjects suffered from severe $(\geqslant 4 \mathrm{~mm})$ unilateral ptosis with levator function $<5 \mathrm{~mm}$ on the affected side whilst restraining frontalis compensation. Blinking and Bell's reflexes were normal. Comprehensive ocular and systemic examinations were otherwise unremarkable. ${ }^{8}$ Informed consents from parents were obtained before the operation.

The surgical technique was a double-trapezoid procedure. After the ends of the two MM strips has been passed through the brow incision over the temporal side, they were pulled tight until the lid rested just above the superior limbus. They were then tied with two 5.0 Ethibond sutures passed through the MM just within the brow incision. The ends on the nasal side were tightened and tied in a similar manner. The excess MM was trimmed and the sling was allowed to retract into the deep brow space. Pulling from the lid margin with a blunt-toothed forceps helped to ensure adequate retraction of the MM into the deep brow tissue and reduced the chance of delayed mesh extrusion. The brow incisions were closed with a $6-\mathrm{O}$ silk suture and a Frost suture was then applied. ${ }^{8}$

The patients were reassessed. Upper lid position, crease height, lid lag or lagophthalmos, best-corrected visual acuity (BCVA), automated refractometry (AR) (KR-7100; Topcon, Tokyo, Japan), and ocular complications were recorded. Institutional Review Board Committee approval was obtained.

Surgical outcome was defined as good, moderate, or poor, on the basis of the criteria described by Manners. ${ }^{18}$

Table 1 Subjects demographics and surgical outcomes

\begin{tabular}{|c|c|c|c|c|c|c|c|}
\hline No. & Sex & $\begin{array}{l}\text { Age at operation } \\
\text { (months) }\end{array}$ & $\begin{array}{c}\text { Follow-Up duration } \\
\text { (years) }\end{array}$ & $\begin{array}{l}\text { Ptosis } \\
(\mathrm{mm})^{\mathrm{a}}\end{array}$ & Outcome $^{\mathrm{b}}$ & $\begin{array}{l}\text { Lagophthalmos } \\
(\mathrm{mm})\end{array}$ & $\begin{array}{l}\text { Lid lag } \\
(\mathrm{mm})\end{array}$ \\
\hline 1 & Male & 7 & 14.3 & 6 & Good & 1 & 1 \\
\hline 2 & Female & 4 & 13.4 & 6 & Good & 0.5 & 1 \\
\hline 3 & Male & 3 & 13.3 & 5 & Good & 1 & 2 \\
\hline 4 & Male & 6 & 13.2 & 4 & Good & 2 & 2 \\
\hline 5 & Male & 11 & 13.2 & 4 & Good & 1 & 0 \\
\hline 6 & Female & 11 & 12.8 & 4 & Good & 1 & 1 \\
\hline $7^{\mathrm{b}}$ & Male & 6 & 12.6 & 5 & Moderate & 0 & 1 \\
\hline 8 & Female & 9 & 12.6 & 5 & Good & 1 & 2 \\
\hline 9 & Male & 6 & 12.6 & 4 & Good & 1 & 1 \\
\hline 10 & Female & 6 & 12.4 & 5 & Good & 1 & 2 \\
\hline
\end{tabular}

${ }^{a}$ Difference in palpebral fissure height $(\mathrm{mm})$ when patient looked in primary position of gaze.

bubject with recurrent ptosis.

Surgical outcome was defined as good, moderate or poor, on the basis of the criteria described by Manners. (see text and ref ${ }^{17}$ ). 
(1) Good: the postoperative lid position is maintained within $1 \mathrm{~mm}$ of the superior limbus in the primary position of gaze.

(2) Moderate: the postoperative lid position drops $>1 \mathrm{~mm}$ below the superior limbus, but remains clear of the visual axis in the primary position of gaze.

(3) Poor: the postoperative lid position drops to obscure the visual axis in the primary position of gaze.

Ptosis recurrence was defined as having moderate or poor surgical outcome at least 2 months postoperatively. BCVA was expressed in Snellen acuity. Negative cylinder method was used to represent astigmatic refractive error.

Questionnaire-based interviews were carried out in the subjects' mother language (Chinese) at the end of the examination by an independent investigator (CL) (Table 2). They were asked to mark their satisfaction regarding lid position, cosmesis, function, and the procedure as a whole on a scale of 1-100 (a score of 100 indicating total satisfaction).

Written informed consents were obtained from all parents and all the children agreed to participate. The study followed the guidelines of the Declaration of Helsinki, and was approved by the ethics committee of the Chinese University of Hong Kong.

We certify that all applicable institutional and governmental regulations concerning the ethical use of human volunteers were followed during this research.

\section{Results}

Subjects' demographic data and surgical outcomes were shown in Table 1. Six were male. Mean \pm standard deviation (SD) age at surgery was $6.9 \pm 2.7$ months (range: 3 to 11 months). After $13.0 \pm 0.6$ years (range: 12.4 to 14.3 years), 9 out of 10 patients achieved good surgical outcome by Manner's criteria. One patient (10\%) had ptosis recurrence at around 3 months postoperatively and his upper lid position was $2 \mathrm{~mm}$ below superior limbus. It was reported in the first paper. ${ }^{8}$ Both parents and patients preferred observation and we did not have

Table 2 Subjective satisfactory scores

$\begin{array}{ll}\begin{array}{l}\text { Compared with the unoperated eyelid } \\ \text { Lid position }\end{array} & \text { How do you grade the position of } \\ \text { your operated eyelid? } & \text { How do you grade the appearance of } \\ \text { the operated eyelid? } & \text { How well does the operated eye } \\ \text { Function } & \text { function? } \\ \text { Procedure as a whole } & \text { How do you grade the result of the } \\ & \text { procedure as a whole? }\end{array}$

Interviews were conducted in subjects' mother language (Chinese) by an independent investigator. Questions were translated in english for reference. the opportunity to explore for the reason of surgical failure. No case of overcorrection was observed.

Four patients had $2 \mathrm{~mm}$ lid lag evident on down-gaze, not noticed in the earlier report (Table 1, Figure 2). ${ }^{8}$ One of them had $2 \mathrm{~mm}$ lagophthalmos and was put on nocturnal lubricant (Duratear, Alcon Laboratories (SA) Ltd.). Both were considered as complications of the sling procedure rather than the type of sling material used. We believe that lid lag or lagophthalmos may worsen with time when surgery is done early in life, as current sling materials fail to grow with the rest of facial structures. No instance of sling extrusion, stitch granuloma, or exposure keratopathy was noted.

Visual and refractive outcomes were shown in Table 3. BCVA of the operated eyes were 20/15 in one, 20/20 in five, and $20 / 30$ in the remaining four patients. Two patients had same BCVA between operated and unoperated eyes, whereas one had one line better BCVA in the operated eye and six had one line worse BCVA in the operated eyes. BCVA was 20/20 for the operated eye and 20/18 for the fellow normal eye in the patient with recurrent ptosis. None of them required occlusion or penalization therapy during the postoperative period. Mean astigmatism was $1.2 \pm 1.0 \mathrm{D}$ (range: 0 to $3.5 \mathrm{D}$ ) and $1.1 \mathrm{D} \pm 1.73 \mathrm{D}$ (range: 0 to $5.5 \mathrm{D}$ ) between operated and unoperated eyes. Mean satisfaction scores were $83.3 \pm 11.8$ (range: 68 to 100 ) for lid position, $77.0 \pm 22.9$ (range: 25 to 100) for cosmesis, $89.4 \pm 5.5$ (range: 80 to 95)

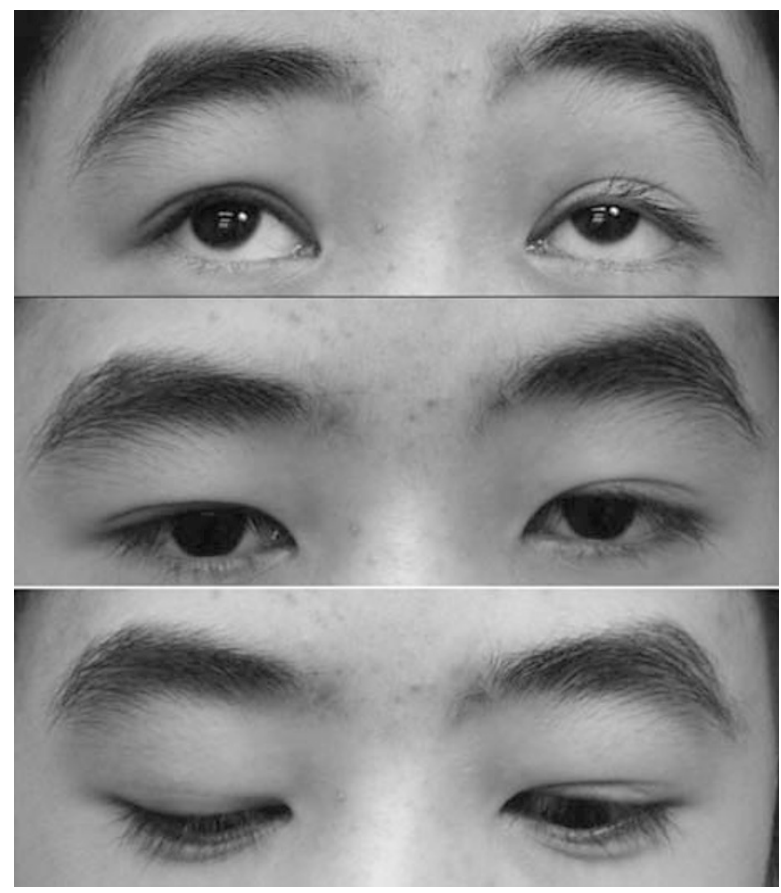

Figure 2 Subject with left-sided MMFS done 13 years ago. Note left frontalis action on up-gaze (above) and primary gaze (central) and lid lag evident on down-gaze (below). 
Table 3 Long-term visual and refractive outcomes after unilateral MMFS operation in infancy

\begin{tabular}{lcccc}
\hline No. & $\begin{array}{c}\text { BCVA } \\
(\text { operated eye) }\end{array}$ & $\begin{array}{c}\text { BCVA } \\
\text { (unoperated eye) }\end{array}$ & $\begin{array}{c}\text { Refractive error } \\
\text { (operated eye) }\end{array}$ & $\begin{array}{c}\text { Refractive error } \\
\text { (unoperated eye) }\end{array}$ \\
\hline 1 & $20 / 30$ & $20 / 25$ & $0.25 \mathrm{D} /-1.75 \mathrm{D} \times 162$ & $-4.25 \mathrm{D} /-2.50 \mathrm{D} \times 162$ \\
2 & $20 / 20$ & $20 / 15$ & $-0.62 \mathrm{D} /-3.50 \mathrm{D} \times 1$ & $-4.25 \mathrm{D} /-0.25 \mathrm{D} \times 127$ \\
3 & $20 / 20$ & $-0.25 \mathrm{D} /-0.50 \mathrm{D} \times 163$ & $0.50 \mathrm{D} /-0.50 \mathrm{D} \times 127$ \\
4 & $20 / 20$ & $1.50 \mathrm{D} /-2.25 \mathrm{D} \times 175$ & $-1.75 \mathrm{D}$ \\
5 & $20 / 30$ & $20 / 20$ & $-0.25 \mathrm{D} /-1.00 \mathrm{D} \times 145$ & $-2.75 \mathrm{D} /-0.25 \mathrm{D} \times 3$ \\
6 & $20 / 30$ & $20 / 20$ & $-2.00 \mathrm{D}$ & $0.25 \mathrm{D} /-0.25 \mathrm{D} \times 131$ \\
$7^{\mathrm{b}}$ & $20 / 30$ & $20 / 18$ & $0.75 \mathrm{D} /-0.50 \mathrm{D} \times 141$ & $-2.25 \mathrm{D}$ \\
8 & $20 / 20$ & $20 / 20$ & $0.25 \mathrm{D} /-0.75 \mathrm{D} \times 150$ & $1.25 \mathrm{D} /-5.50 \mathrm{D} \times 1$ \\
9 & $20 / 20$ & $20 / 30$ & $0.75 \mathrm{D} /-1.00 \mathrm{D} \times 175$ & $-0.75 \mathrm{D} /-1.12 \mathrm{D} \times 8$ \\
10 & $20 / 20$ & $20 / 10$ & $-0.87 \mathrm{D} /-0.75 \mathrm{D} \times 142$ & $P$-value $=0.836$ for astigmatic error \\
\hline
\end{tabular}

aBCVA, best-corrected visual acuity.

bSubject with recurrent ptosis.

for function, and $86.8 \pm 6.3$ (range: 80 to 98) for overall satisfaction to the procedure (Table 2).

\section{Discussion}

We acknowledge the limitations of our small sample Chinese cohort with only unilateral simple myogenic ptosis operated by a single surgeon. Preoperative vision, refraction, lid lag, and lagophthalmos were not documented, without which we were not able to draw any conclusion on whether early unilateral ptosis correction may have any effect on long-term visual and refractive development. ${ }^{15,16}$ Subjects maintained excellent visual outcomes without occlusion and penalization therapy postoperatively.

In adults, a negative social connotation is often linked with blepharoptosis. ${ }^{19}$ Ptosis correction not only improves superior visual field, but also vision and health-related quality of life. ${ }^{20}$ Severe unilateral ptosis in children is, moreover, associated with astigmatism, myopia and amblyopia, and abnormal head posture. ${ }^{15,16}$ Corrective surgery thus carries considerable functional and developmental implications. ${ }^{17}$ There was no consensus regarding the timing, type of operation, unilateral or bilateral surgery, sling pattern, or the choice of sling material for unilateral infantile ptosis. ${ }^{21}$ This may be attributed to the lack of an ideal operation, sling, or long-term outcome data. Some surgeons would treat young children with ptosis using a synthetic material and expect them to have a second operation with autogenous fascia lata when they grow older. However, a synthetic material, which provided a long-term high success rate, might provide another treatment option.

AFL has been and continues to be the gold standard of FS material in older children and adults since its introduction by Payr and Wright. ${ }^{6}$ However, use in children younger than 3 years is generally not recommended with reasons. ${ }^{2,3}$ The fascia lata is not well developed before the age of 3 years making the harvest of adequate fascia technically challenging. Thigh scars stand out more obviously in young children ${ }^{1-3,6,22}$ making it unappealing to most parents. Complications related to AFL harvesting such as muscle herniation and haematoma occasionally occur. Recently, Leibovitch et al reported about four infants under 1 year of age who have undergone successful brow suspensions using AFL with a single thigh incision measuring $6-8 \mathrm{~cm}$. We also commended recent reports about small incisions (two incisions, $2-2.5 \mathrm{~cm}$ long) or endoscopic (one incision, smaller than $2 \mathrm{~cm}$ ) techniques of harvesting AFL with the aid of specialized equipments and minimally invasive methods. ${ }^{23,24}$ Yet, before such practice becomes popular among most ophthalmic plastic/paediatric ophthalmic surgeons treating children with ptotic lids, the availability of an ideal sling material is still our main concern.

Autogenous palmaris longus tendon (PLT) is the most commonly used tendon graft in orthopaedics. It can be safely harvested through small incisions (two incisions, $1 \mathrm{~cm}$ ) and is completely developed at birth. With a higher tensile strength than an equal portion of FL because of its densely arranged connective tissues fibres, it is considered as a 'living suture'. Our group has earlier reported that PLT showed remarkable stability (over 80-104 months) and minimal donor site morbidity in children (as young as the age of two). ${ }^{25-27}$

Ptosis recurrence was found in up to $30 \%$ of cases in certain series after MMFS. ${ }^{28}$ Soft tissue complications including sling extrusion, wound granuloma, or infection occurred in $0-35 \%$ of cases. ${ }^{29}$ We suspect that different sling preparation and surgical techniques may at least, in part, account for such wide range of outcomes. 
We take the following steps to preserve the strength of the mesh before fibrovascular growth sets in and to minimize mesh end exposure or contact with thick brow skin/cilia, in which bacteria may harbour or track down the pilosebaceous units.

The meshes were cut along the long axis of oval pores; cutting perpendicularly gave rise to a more stretchable, but weaker sling. ${ }^{9}$ The meshes were soaked in antibiotic solution before implantation. The double-trapezoid technique of sling passage allowed fine adjustment of lid contour, maximal (four) connections with and vertical lift transmitted from sites of strongest frontalis action (along brow cilia) to upper lid margin. ${ }^{8}$ We avoided the central high forehead incision where the frontalis action was weaker. We sutured the sling ends together with two 5.0 Ethibond (Ethicon) instead of tying them with each other to decrease bulk. $8-10 \mathrm{~mm}$ sling ends were left to be rethreaded towards the central brow incision, burying them horizontally, deep to the frontalis. Pulling on lid margin afterwards helped further sling retraction before brow wound closure.

To the best of our knowledge, this study reports the longest follow-up outcome of FS operations for the patients of $<1$ year age group. Our results after 13 years were encouraging: the efficacy of MMFS in our series was up to $90 \%$. It compared favourably with many series of AFL (92-100\%) and surpassed most currently available allogenic or synthetic sling materials. ${ }^{1-6,17,30}$ Correction with MM may obviate the need of second operation.

Surveying paediatric patients becomes increasingly important for studying maxillofacial, orthopaedic, hearing, and cardiothoracic disorders. ${ }^{31,32}$ Psychosocial impact of strabismus correction in adolescent subjects was reported by Menon et al. ${ }^{33}$ Taherian et al ${ }^{34}$ have recently conducted a comparative study of the subjective and objective grading of ptosis surgery outcome in an adult cohort. Chesney et $a l^{35}$ concluded, after surveying 116 children and adolescents and their 115 parents, that issues identified by the children/teen respondents were either not addressed at all by parents or were not noted as frequently by them. Their study showed that children and adolescents could contribute important informations about their health care experience and questioned the appropriateness of asking only parents or guardians on behalf of their children.

In the current study, we introduce, for the first time, subjective satisfaction scores as a long-term outcome parameter in infantile ptosis correction after the subjects reach adolescence. A high satisfaction score of $88.0 \pm 6.9$ (range: $80-98$ ) was marked towards MMFS as a whole. The mean score of cosmesis was 77. However, it should be noted that one patient only scored 25 . The asymmetry was one of the concerns. Therefore, some surgeons may advocate performing bilateral surgeries for unilateral ptosis cases to improve symmetry and cosmesis.

\section{Conclusion}

Long-term stability of AFL is well established in older children, but the role in infants is yet to be defined. When early ptosis correction is indicated to treat amblyopia or to relieve abnormal head posture, use of a synthetic sling material may be justified in small children. In view of the low recurrence rate $(10 \%)$ and absence of serious complication after 13 years' follow-up, the use of MMFS can be considered in infants aged less than one with more urgent indication of ptosis repair. Time-tested multi-faceted benefits from early ptosis correction using appropriate synthetic sling material in infants should be carefully weighed against the tradition of delaying surgery for AFL harvesting.

\section{Acknowledgements}

Kelvin KL Chong helped in data collection and manuscript preparation, Dorothy SP Fan in hypothesis generation, data collection and manuscript preparation, Connie HY Lai in data collection, Srinivas K Rao in manuscript preparation, Philip TH Lam in data analysis and manuscript preparation and Dennis SC Lam in protocol design and surgeons of the patients.

\section{References}

1 Kemp EG, James CR, Collin JR. Brow suspension in the management of ptosis: an analysis of over 100 cases. Trans Ophthalmol Soc UK 1986; 105: 84-87.

2 Crawford JS. Repair of ptosis using frontalis muscle and fascia lata: a 20-year review. Ophthalmic Surg 1977; 8: 31-40.

3 Crawford JS. Congenital blepharoptosis. In: Smith BV, Dellar RRC (eds). Ophthalmic plastic and reconstructive surgery, Vol 1. Recent trends in ptosis surgery. St Louis: CV Mosby, 1987; 1, pp 643-645.

4 Wasserman BN, Sprunger DT, Helveston EM. Comparison of materials used in frontalis suspension. Arch Ophthalmol 2001; 119: 687-691.

5 Wagner RS, Mauriello JA, Nelson LB, Calhoun JH, Flanagan JC, Harley RD et al. Treatment of congenital ptosis with frontalis suspension: a comparison of suspensory materials. Ophthalmology 1984; 91: 245-248.

6 Leibovitch I, Leibovitch L, Dray JP. Long-term results of frontalis suspension using autogenous fascia lata for congenital ptosis in children under 3 years of age. Am J Ophthalmol 2003; 136: 866-871.

7 Sharma TK, Willshaw H. Long-term follow-up of ptosis correction using mersilene mesh. Eye 2003; 17: 759-761.

8 Lam DS, Gandhi SR, Ng JS, Chen IN, Kwok PS, Chan GH et al. Early correction of severe unilateral infant ptosis with the mersilene mesh sling. Eye 1997; 11: 806-809.

9 Downes RN, Collin JR. The mersilene mesh sling-a new concept in ptosis surgery. Br J Ophthalmol 1989; 73: 498-501. 
10 Downes RN, Collin JR. The mersilene mesh ptosis sling. Eye 1990; 4: 456-463.

11 Hintschich CR, Zurcher M, Collin JR. Mersilene mesh brow suspension: efficiency and complications. Br J Ophthalmol 1995; 79: 358-361.

12 Elder MJ. Mersilene mesh and fascia lata in brow suspension: a comparative study. Ophthalmic Surg 1993; 24: 105-108.

13 El-Toukhy E, Salaem M, El-Shewy T, Abou-Steit M, Levine $\mathrm{M}$. Mersilene mesh sling as an alternative to autogenous fascia lata in the management of ptosis. Eye 2001; 15: 178-182.

14 Mehta P, Patel P, Olver JM. Functional results and complications of mersilene mesh use for frontalis suspension ptosis surgery. Br J Ophthalmol 2004; 88: 361-364.

15 Dray JP, Leibovitch I. Congenital ptosis and amblyopia: a retrospective study of 130 cases. J Pediatr Ophthalmol Strabismus 2002; 39: 222-225.

16 Cadera W, Orton RB, Hakim O. Changes in astigmatism after surgery for congenital ptosis. J Pediatr Ophthalmol Strabismus 1992; 29: 85-88.

17 Tanenbaum M. Childhood ptosis: diagnosis and treatment. Int Paediatr 1990; 5: 244-248.

18 Manners RM, Tyers AG, Morris RJ. The use of Prolene as a temporary suspensory material for brow suspension in young children. Eye 1994; 8: 346-348.

19 Warwar RE, Bullock JD, Markert RJ, Marciniszyn SL, Bienenfeld DG. Social implications of blepharoptosis dermatochalasis. Ophthal Plast Reconstr Surg 2001; 17: 234-240.

20 Federici TJ, Meyer DR, Lininger LL. Correlation of the vision-related functional impairment associated with blepharoptosis and the impact of blepharoptosis surgery. Ophthalmology 1999; 106: 1705-1712.

21 Small RG. The surgical treatment of unilateral severe congenital blepharoptosis: the controversy continues. Ophthal Plast Reconstr Surg 2000; 16: 81-82.

22 Wheatcroft SM, Vardy SJ, Tyers AG. Complications of fascia lata harvesting for ptosis surgery. Br J Ophthalmol 1997; 81: 581-583.

23 Malhotra R, Selva D, Olver JM. Endoscopic harvesting of autogenous fascia lata. Ophthal Plast Reconstr Surg 2007; 23: 372-375.
24 Kashkouli MB. A novel technique for small-incision fascia lata harvesting without a fasciatome for the frontalis suspension procedure. Orbit 2007; 26: 203-206.

25 Lam DS, Lam TP, Chen IN, Tsang GH, Gandhi SR. Palmaris longus tendon as a new autogenous material for frontalis suspension surgery in adults. Eye 1996; 10: $38-42$.

26 Lam DS, Ng JS, Cheng GP, Li RT. Autogenous palmaris longus tendon as frontalis suspension material for ptosis correction in children. Am J Ophthalmol 1998; 126: 109-115.

27 Wong CY, Fan DS, Ng JS, Goh TY, Lam DS. Long-term results of autogenous palmaris longus frontalis sling in children with congenital ptosis. Eye 2005; 19: 546-548.

28 Whitehouse GM, Grigg JR, Martin FJ. Congenital ptosis: results of surgical management. Aust N Z J Ophthalmol 1995; 23: 309-314.

29 Mehta P, Patel P, Olver JM. Management of mersilene mesh chronic eyelid complications: a systematic approach. Eye 2004; 18: 640-642.

30 Wilson ME, Johnson RW. Congenital ptosis. Long-term results of treatment using lyophilized fascia lata for frontalis suspensions. Ophthalmology 1991; 98: 1234-1237.

31 Zou YH, Zhuang HX, Wang SJ, Xue F, Dai P, Han DY. Satisfactory surgical option for congenital microtia with defects of external auditory meatus (EAM) and middle ear. Acta Otolaryngol 2007; 127: 705-710.

32 Cheung LK, Loh JS, Ho SM. Psychological profile of Chinese with cleft lip and palate deformities. Cleft Palate Craniofac J 2007; 44: 79-86.

33 Menon V, Saha J, Tandon R, Mehta M. Khokhar S study of the psychosocial aspects of strabismus. J Pediatr Ophthalmol Strabismus 2002; 39: 203-208.

34 Taherian K, Atkinson PL, Shekarchian M, Scally AJ. Comparative study of the subjective and objective grading of ptosis surgery outcomes. Eye 2007; 21: 639-642.

35 Chesney M, Lindeke L, Johnson L, Jukkala A, Lynch S. Comparison of child and parent satisfaction ratings of ambulatory pediatric subspecialty care. J Pediatr Health Care 2005; 19: 221-229. 